\title{
Creation and EXtension OF MEANING IN Professional COMMUNiCATION
}

\author{
LARISA ILINSKA \\ Riga Technical University, Latvia \\ larisa.ilinska@rtu.lv \\ OKSANA IVANOVA \\ Riga Technical University, Latvia \\ oksana.ivanova_1@rtu.lv
}

\begin{abstract}
The application of different language resources in professional communication reveals the role of cognition in information processing, the interpretive function of language in knowledge construction, and the interrelation of linguistic and extra-linguistic environments. The aim of the present paper is to examine the development of the language of science and the way it is influenced by history, technology, media, genre, and culture. Integrating cognitive approach and pragmatic analysis, the ways of meaning creation and meaning extension have been studied in the popular science texts. Creative thinking and imagination are considered responsible for innovative, creative and insightful thought in general, and, sometimes, for a much wider range of mental activities.
\end{abstract}

Keywords: professional communication, cognition, meaning creation, information structure, intertextuality, associative thinking

\section{Introduction}

At present, professional communication includes a wide range of disciplines, incorporating a diversity of rhetorical contexts and situations. As any field of human activity, professional communication is a social phenomenon. Scientists cooperate and share best practices in order to achieve commercial success and professional recognition. They should master general skills of logical reasoning and argumentation based on critical and creative thinking in order to explain their ideas and persuade readers. It can be stated that readers' reaction towards the information communicated depends on the author's command of scientific language and the art of rhetoric. Therefore, the investigation of professional communication as a cognitive structure can be based on the study of rhetoric as a theoretical foundation and the popular science text as a form of professional 
communication. In search of meanings to denote new phenomena, discoveries, inventions and innovations, a new language has been created to communicate science, it is the language of the popular science texts. Language is one of the parts of a cognitive system, which comprises perception, emotions, categorization, reasoning and other mental processes.

The application of different language resources in professional communication reveals the role of cognition in information processing, the interpretive function of language in knowledge construction, and the interrelation of linguistic and extra-linguistic factors. Cognitive approach to text analysis focuses on the processes involved, applying various empirical modes of research. The integration and comprehension of the cognitive processes in text interpretation, which are characterised by cross-linguistic and cross-cultural features, provide a higher level of linguistic competence. Cognitive science studies how external and new information is processed and transformed into meaningful knowledge, which is based on cognitive processes responsible for decoding of meaning.

At present, the cognitive approach to text interpretation is increasingly related to the study of associative meaning networks. The referential and dynamic network relations were proposed by Irvine (2016, p. 23). He maintains that “... we make mental relations between perceptions and thought, and generate further relations among thoughts connected in vast networks of collectively understood signs spanning many states of time". Modelling the creative use of language resources through the application of integration networks to describe processes of conceptual blending was investigated by different authors (Fauconnier and Turner, 2002).

The present paper investigates the problem of meaning construction within multiple networks of human knowledge representation. In this context, the meaning-making process involves assembling information stored in long-term memory into a momentary working memory. Successful interpretation takes place through the interaction between previously stored knowledge and mental models evoked instantly.

\section{The Language of Science}

The language of science is often defined as a system of professional communication, a system of meaning creation, and a subject for scientific discussion.

Communication can succeed or fail because of the complex possibilities involved in meaning construction. From a cognitive perspective, communication is based on mental states and shared knowledge (Clark, 1996). The same text can be perceived and interpreted differently in different periods of time and different cultures. 
During the $17^{\text {th }}$ and $18^{\text {th }}$ century, the real separation between science and mythical thought occurred. It was necessary for science to build itself up against the old generations of mythical and mystical thought. For example, Bacon, Descartes, Newton and many other philosophers and scientists attempted to create a new style of scientific writing to avoid the problems of language ambiguity by formulating new conventions in order to resolve the issues related to the complex interaction between reasoning, rhetoric and imagination (cf. Stephens, 1975). At that period of time, characteristics of mythological thought (figurative sensibility and sensitivity to emotion) were considered a delusive world, whereas the real world was a world of mathematical properties, which could only be grasped by the intellect (cf. Levy-Strauss, 1978 [2014]). The frame of scientific and technical discourse implied the application of rules and conventions that limited the play of words or double meanings, as the main objective was to avoid the use of figurative language.

However, today it is next to impossible to find a popular science text that would be purely neutral and expressed only in an internationally appropriate language. Contemporary popular science text is not at all moving away from the figurative language and mythical thinking, classical images and Biblical writings but it rather is incorporating them in scientific reasoning and explanation. The search for universal language, which can be traced back to ancient Greek philosophy and even before in the idea of sacred words within mythologies, saw one of the most famous breaking points demonstrated by Wittgenstein (1974), when the philosopher upturned his own previously developed theory of logically ideal language, admitting the importance of things 'that cannot be said'. Myths are disconnected from history, from change, from the flow of time, they are equally relevant at all moments in the life of culture (cf. Doniger, 2011). Many philosophers returned to interpreting myths in an attempt to discover their significance for human understanding of the events in the course of time. Classical mythology became the rich source of modern scientific terminology, e.g., Zeus virus, Trojan horse malware, Apache Cassandra database. In many cases, the traditional well-known meaning is lost.

Literary characters and celebrities are also the rich source of modern scientific terminology, such as Faust program, Chernobyl virus, Anna Kournikova worm, Ceylon programming language. At present, rhetoric usually operates at the language level, but also, more or less frequently, at the contextual level of communication to get acquainted with new meanings of well-known lexical items.

Thanks to unexpected or sometimes unimaginable combinations, a lexical unit that has lost its semantic content may come to new life in a new setting, especially in the formation of terminological units, e.g., worm wheel, dogtooth spar crystals, herring-bone gear, catfishing, digital detox, shower rose, apron wall, daisy chain network, bent tail dog. Due to the development of ICT and digital media, the language of science is greatly influenced by the development of popular science texts. For example, such lexical units as robot, cyborg, Android, zero-gravity, 
telepathy, teleportation, telekinesis, time travel and many others were coined in popular science texts.

As it follows from the discussion above, popular science texts develop a special language. The potential of all natural language resources may create the endless number of meanings, which update the vocabulary and expand its limits. Language in use is seen as an "interface" (Croft, 2000) mediating between the "conventions of a language (those aspects of use that make language stable) and mechanisms that result from deviation from convention resulting in language change" (in Evans and Green 2011, p. 109).

In any process of communication, there are a number of meanings or levels of comprehension. According to Geeraerts $(2016,531)$, "[l]anguage is studied not as if it were a separate and autonomous cognitive module, but as a reflection of general conceptual organisation, categorisation principles, processing mechanisms, and experimental and environmental influences".

One more aspect, namely cultural one, was argued by Gabriela Pohl (2004, p. 3 ), "it is difficult if not impossible to come up with universally applicable rules for language use as each culture has more or less culture-specific pragmatic features," even if many of them are implicit. The opinion that the scientific and technical text is devoid of cultural influences is due to the judgement that the laws of physical sciences are above the constraints of any one national culture; however, it is not true because "... science is not just a collection of laws, a catalogue of facts. It is a creation of the human mind, with its freely invented ideas and concepts" (Einstein and Infeld, 1938). Such aspects as the play of words, implicatures, metaphors and allusions are very often linguistically and culturally bounded and therefore dissimilar in different languages. They present the main challenges for text decoding. In order to perceive a text adequately, a reader needs not only linguistic and metaphoric competence, background knowledge and information processing skills, but also associative thinking and imagination.

\section{Information Structure}

The contemporary language of science has changed and developed due to different factors: interdisciplinary character of scientific discourse; emerging domain of Internet linguistics; development of digital rhetoric; development of popular science texts resulting in an apparent tendency for hybridization of genres; and shift from formal to more colloquial style deviant from the selected register and genre. The reader should be able to interpret information cognitively, comprehending the results of application of non-typical elements, including different foregrounding techniques (cf. Leech, 2008, 60), and decoding their effects in the perception of the text. According to Leech $(1970,121)$, foregrounding has been claimed to be a basic principle of aesthetic communication. Foregrounding can also be manifested through rhetorical 
strategies (stylistic devices, figurative language), causing the reader's attention to shift from what is communicated to how it is communicated. Foregrounding may contribute to the total meaning of text expressed in references, images, quotations or citations (Montes-Alcalá, 2013, 216) and, therefore, it implies the analysis of the factors influencing the response of the reader to the devices applied. Van Peer $(1986,22)$ was the first to consider the notion of foregrounding as a pragmatically driven phenomenon, which requires cognitive interpretation. The scholar states that foregrounding refers to the dynamic interaction between the author, text and the reader. It is used to emphasise the aesthetic value the author expresses in the text to satisfy the aesthetic needs of the reader in perception of such devices. Thus, foregrounding should be analysed at different levels to establish a coupling between different layers of meaning of the text. Content and structure of science texts are also continuously in the process of reorganisation because "text is influenced by such issues as social rules, group purposes, and cultural constraints" (Bhatia, 1993, 18).

Nowadays in order to investigate the way how background knowledge influences the creation of new meanings in the course of text interpretation, information structure is analysed in terms of three basic dichotomies, namely, focus vs. background, topic vs. comment, and given vs. new. To some extent, all three dimensions of the information structure are related to the concept of intertextuality because they represent the interaction between the known and the unknown information. However, it is the third dichotomy, namely, given vs. new, where this relation is most evident, because this dimension characterises how the given text is related to the preceding texts and the preceding knowledge (cf. Ilinska et al., 2015).

The way that readers treat the preceding texts is more complicated than simply whether they recognise and understand them. The theory of intertextuality is based on the premise that a text alone is not whole and that it functions within an open system (cf. Worton, Still, 1990).

Authors of science texts usually restrict the amount of new information communicated and present it in a logical sequence. The success of communication usually depends on the volume of given information, i.e., knowledge shared by the highest possible number of readers, and the new information characteristic of this type of texts.

Researchers also need to find a balance between the subject matter and scientific reasoning by efficiently using the potential of language resources. In general, popular science texts tend to follow a linear thematic progression, make references (using the figurative language) to everyday experience in order to make scientific theories, models and concepts foregrounded to attract readers' attention.

Rhetoric is fundamental in science popularisation. Figurative language is dynamic, influenced by a number of factors that determine its communicative intention. Rhetorical devices help stimulate reader's imagination, create a sense of proximity between the author and the reader, who perceives the author as one like them (cf. Hezaveh, 2014). They also expand knowledge creating connections 
between previous experiences and new information. There is a cognitive mechanism behind the relationship between rhetorical devices, ways of interpretation or meanings and their effect.

At present, rhetoric is so deeply rooted in the language of science that it is almost impossible to find communicative situations in which these devices are not used. According to Ghiazza (1985), rhetoric is the art of fine speaking and good style of writing, an expressive and effective way of communication, full of echoes, associations and semantic nuances, which enrich language through unusual and commonly used lexical elements.

For example, in order to understand and interpret the communicated information in the book "Travels in Architecture" by Harbison, the reader is supposed to be aware of the imagery of the Bible, Greek mythology, the Renaissance, including Mannerism (artistic style that predominated in Italy from the end of the High Renaissance in the 1520s). The language of the popular science text is complex; it contains a lot of allusions, epithets, similes and other rhetorical devices:

(1) In the next generation at the Casa Buonarroti in Florence, Michelangelo's pronipote, known as Michelangelo the Younger, created his own modest studiolo, part of an elaborate Mannerist shrine to his great kinsman that turned Michelangelo's life into ritualized images and embedded a few small pieces of his work in the exquisite setting like flies in amber (Harbison, 2009, pp. 162-163).

In the process of interpretation, the level of intertextuality of the text increases requiring activation of various levels of background knowledge. Intertextuality allows allusions to go beyond the scope of individual piece of writing and connect the works of the world cultural heritage and the reader's background:

(2) Clouds of infant angels surround the shrine and metal rays of light shower down upon it, issuing from an oval window of yellow alabaster like the sun emerging from clouds and representing the power of the Holy Spirit to inform the pope directly (Harbison, 2009, pp. 175-176).

The rhetorical devices express something that a text otherwise does not provide and this something is meaning often hidden in special words and images the authors use in order to illustrate, to create additional meanings and to achieve and facilitate the needed stylistic effect. Thus, the interpretation of the popular science text should be carried out taking into account the pragmatic aspect, i.e., the information communicated in the context of professional interaction, and the cognitive aspect, i.e., interpretation of the text by participants of professional communication. 


\section{Meaning as a Cognitive Structure}

It should be taken for granted that meaning is basically a cognitive structure. There are two general theories of meaning, which are divided into two broad subclasses: a semantic theory, i.e., referential theory of meaning (Carnap 1937; Tarski 1944; Leech 1981), and a foundational theory of meaning, i.e., mentalistic, cognitive, conceptual theories of meaning (Jackendoff 1990; Fauconnier 1994; Davis 2002), where meanings are identified with mental structures.

The referential theory of meaning helps explain the knowledge of semantic meaning without explaining the way expressions obtain their meaning, and thus it does not possess any connection with psychological objects of reality. The foundational theories of meaning, instead, imply mental images of meaning produced by a language user. Mental images can communicate more, sometimes indirectly. The idea behind the cognitive theory explains why the understanding of meaning mainly depends on the skills of a language user, i.e., verbal perception and logical grasp. The understanding of meaning of an expression might often appear to be distinct irrespective of the conceptual perception of a notion.

According to Langacker ([1991] 1992, p. 35), meaning of a sentence is the "image" of "a particular event known in full detail", and this image becomes the content of a communicative intention. There is something like a conventional core meaning for lexical items, but it is rather schematic, and, as a matter of fact, this conventional meaning is an abstraction from the different contexts where that particular word has been encountered before (Evans \& Green, 2011, p. 213).

The contemporary pragmatic approach assumes meaning as a contextualization pattern (Taylor 2003), where context encompasses immediate linguistic context and shared world knowledge patterns. Whereas formal knowledge facilitates making accurate identification of forms from a minimum number of visual cues, subject-specific, cultural and pragmatic knowledge determines not only a personal reconstruction of the meaning of a text but also its depth and richness (cf. Eskey, 1986).

Based on cognitive science and pragmatics, the present study follows Sperber and Wilson $(1986,2002)$ in considering pragmatics as an information processing system. In this view, meaning is merely an inferential product of the integration of basic lexical properties and surrounding contextual information, processed through cognitive and pragmatic operations.

In cognitive linguistics, concepts are considered to be constituents of thought, a kind of mental spaces (Lakoff, 1987), which are used for explanation of such phenomena as categorization, inference, memory, learning and decision-making. Concepts establish relationships between knowledge and reality linking a conceptual theory with a theory of knowledge. Concepts aim at investigation of structural relationships of natural languages within a particular linguistic system. "The symbolic resources of a language generally provide an array of alternative images for describing a given scene, appearance, landscapes etc." (Langacker, 1991, p. 12). Many words convey several concepts (Trask, 2004) if a word is found to be capable of conveying at least two concepts, the wealth of expressive 
resources of a language depends on the degree to which polysemy has developed in the language.

Effective human symbolic communication requires some unique forms of conceptualization. Speakers often create figurative analogies when the resources of language are insufficient to express themselves so as to reflect their point of view. Therefore, such linguistic constructions can be conceptualized as mental categories or cognitive symbols.

Categorization is one of the primary principles of conceptual and linguistic organisation. Categories are the basic elements of human cognition formed through our interaction with the world. Lakoff (1987, p. 5) argues that ongoing sorting process is categorization. The extension occurs when we categorize new experience providing creative extension of the category to the current situation (cf. Langacker 1999, pp. 4-6). The expressive potential of the whole vocabulary increases.

Different cognitive mechanisms are used in meaning creation. There are three most distinct cognitive devices: categorisation, preconceptual image schemata and metaphorisation (cf. Botha, 2012). These devices are interrelated in such a way that in the process of meaning creation conceptual blending takes place. To create meaning, they function on various levels of language, representing the cultural background of the language community.

\section{Cognition, Context and Communication}

Relations between meaning and context are of particular importance as they represent an interactive process that facilitates cognition and productive communication. It can be stated that context makes communication possible. The notion of context is a key factor that differentiates approaches to text interpretation. The concept "context" is used in many disciplines, e.g., philosophy, psychology, linguistics, cognitive science, communication studies, etc. The generally accepted meaning of the term "context" is a set of circumstances that frame an event or an object. In cognitive linguistics, Croft and Cruse (2012, pp. 102-103) proposed a four-fold classification of the context, inclusive of linguistic context, physical context, social context and stored knowledge. Linguistic context includes "previous discourse," "immediate linguistic environment," and "types of discourse". On the other hand, the stored knowledge refers to "a vast store of remembered experiences and knowledge" against which messages are processed (Croft and Cruse 2012, p. 103). The stored knowledge involves related frames that structure human understanding of a concept, and experiences of human interaction with the environment.

Bastien (1999) distinguishes between two opposite views about the role of context in human cognition. Context is either considered as a set of general processes that modulate different instances of knowledge or as a component of 
cognition determining the conditions of knowledge activation. These two opposite views underline that context may have an internal or external nature. On the one hand, context is an external object relative to a given object; on the other hand, context belongs to an individual representation of the situation or reality. According to the second viewpoint, "context cannot be separated from the knowledge it organizes, the triggering role context plays and the field of validity it defines" (Bastien 1999). Researchers (e.g., Domaneschi et al., 2016) also study the effect of cognitive effort in interpreting communicative messages involving pragmatic enrichment. Janssens and Schaeken (2016) argue that a major role in interpretation is played by the content of the arguments suggesting that context and content are fundamental in the interpretation process.

Contemporary scientific research in linguistics depends on the results of the study of human mind and its role in the decision-making process.

The difference between the real world and our conceptual understanding of it may be codified as the distinction between situation and context. Thus, context is the theoretical construct of mental spaces (Fauconnier, 1994, p. 16). Langacker (1991, 119) suggests that we can view the mental space as the current discourse space (created in on-gong conversion) construed as being shared by the author and the reader as a basis for communication at a given moment (at a given situation).

Communication is a distributed cognition and, consequently, a blend of mental spaces. The concept of mental blend was originally developed to understand figurative speech (especially metaphors) in the framework of cognitive semantics. The complex processing of information makes possible the creation of conceptual meaning through figurative language in use. "Blending, like conceptual metaphors, cannot in itself account for the difference we perceive between the communicative and the aesthetic, between the literary and the common" (Freeman 2006, p. 110). Mental blending concerns the fusion of different cognitive scripts, schemata, or mental models, which signify a prototypical representation of experiences not only in a conscious, but often in subconscious manner. They cover the range between sensorial and abstract expressions. They are also central to multimodal and dynamic fields of communication when diachronic and synchronic processes of mental blending assure a joint frame of understanding.

\section{Empirical Evidence}

The empirical part of the present research deals with the analysis of mental images based on allusive references characteristic of popular science texts. Mental images usually have more than one meaning, and communication is successful if the author and the reader share the same knowledge, 'speak the same language' or 'share a code' (cf. Barthes, 1964). Texts with many allusions are rich in mental images evoked, but they will achieve the result in text decoding if a reader has necessary background knowledge. Appealing to life experience of readers, mental images increase aesthetic perception, creative imagination, and evoke a great 
number of associations. Most frequently allusion is defined as a kind of reference to a well-known work of literature, work of art, a historical figure, person, place, or event used to evoke certain associations.

The author chooses a particular image to describe the personage, event or situation for communicative purposes. The choice of images results in different meaning linking constructions, which determine different conceptualisation of the structure of the event. As the combination of meanings may sometimes communicate even more information than the text conveys, the reader must understand, which meaning is contextually appropriate.

Allusions can often derive from recent and contemporary events or they can recreate a preceding text from the distant past, as in the following example:

(3) ...The ironic attitude says: "Nothing I do really matters. We can only live in and create fictions. So we may as well just distract ourselves with bread and circuses, with food and entertainment, rather than take care of our environment, others, and ourselves." (Ellin 2006, p. 99)

According to Merriam-Webster's Online Dictionary, the phrase that appeared in Juvenal's Satires alludes to the Roman emperors' organisation of grain handouts and gladiatorial games for the people.

Nowadays the new meaning of a well-known expression "bread and circuses" is commonly used in the cultural and especially political context. The meaning of the phrase is often to generate public approval not by excellence in public service, but by distraction or satisfying the most immediate needs and requirements. In this text, it captures a certain cynical political view that the masses can be happily kept with fast food and entertainment.

Allusions encode a great amount of information expressed in one word or phrase. It is a powerful tool that in a few seconds can evoke a range of interrelated meanings and associations. The potential of allusions is enormous because in a new context they can create a humorous, ironic, satiric or even sarcastic effect. Allusions are based on the extension of meaning and, simultaneously, facilitate compression of information.

Authors often allude to several different sources simultaneously in order to create new associations or make readers evaluate and compare the given events in the context of others.

(4) Complementarity departs from Modernist binary logic because it does not regard the pair as oppositional nor does it seek a synthesis or resolution. Rather, it understands each as not only allowing the other, but also embracing or embodying the other. Prometheus's punishment of having his liver eaten each day by vultures and healed each night suggests the importance of darkness for becoming whole or healing, even if the harm will inevitably come again. Adam and Eve's banishment from the garden allowed for agriculture and childbearing, not to mention architecture and clothing. 
Although the Tower of Babel faltered, it allowed for diaspora and cultural diversity (Ellin, 2006, p. 92).

The gods of Mount Olympus chained Prometheus to a rock and sent an eagle each day to feast on his flesh to punish him for giving mankind fire. In the story of the Tower of Babel, having found out what the humans were doing, the God destroyed the tower and forced everyone to speak different languages so that they would not understand each other and would not be able to build the tower again.

Thus, allusions enable authors to draw a line to world knowledge and events, demonstrating the universality of past experiences and their modified reoccurrence in a new period.

Popular science texts in their nature are multi-layered and the perception of allusions takes place at various levels since they are able to be spread across different contexts. At the same time, using allusions authors expect that the reader is familiar, to some extent, with the references made, otherwise the desired effect will be lost.

In the following example, the text alludes to the Tower of Pisa to emphasise the idea of architects resisting the importance of the energy-conscious structures.

(5) Like the tower out in Pisa, architects and engineers were resisting the importance of the energy-conscious building for a long time. (Gonzalo, Habermann 2012, p. 27)

The Tower of Pisa has its widely known characteristic feature - an 18-degree slope, which is ironically compared with the behaviour of architects in realisation of energy-conscious building. The social and cultural knowledge ensures the success of communication of the meaning of the allusion.

Intelligence and reading experience are required to interpret all clues given in the text, both explicit and implicit (cf. Leppihalme 1997, p. 20).

Analysing Example 6, it should be noted that an allusion can be seen as a type of extended metaphor (e.g., Skrebnev 2000). According to Langacker (1987), metaphor is dominant in shaping the meaning of a text. Conceptual metaphors activate reader's cognition and spontaneously stimulate the emergence of a similar concept that not necessarily should be based on physical experience. Such metaphors usually have a very strong and intuitive association that rests in readers' minds and evokes when the metaphor is encountered.

(6) The debt spider has devoured farms, homes and whole countries that have become trapped in its web (Brown 2008, p. 1).

Some metaphorical terms create their own inner context, which may trigger a wide range of associations encoded in various components of their meaning (Langacker, 1987, p. 113). The perception of metaphor also heavily depends on the use of previously existing conventional conceptual metaphor in the long-term memory, which forms the situational, discourse or bodily context "providing a 
personal framework of analysis which integrates the dependence of metaphorical mind on the surrounding physical, social, and mental environment" (Kövecses, 2015, p. xi).

This means that many things depend on the preamble that might facilitate the understanding of the metaphorical expression in the context, i.e., previously encountered metaphor with similar contextual meaning would be of great assistance in understanding and identification of a new extended metaphor (allusion) in a text.

In cognitive science, the study of metaphor has gained a new perspective as this theory considers metaphor not only a purely linguistic or rhetorical resource but a cognitive phenomenon, which is fundamental to the construction of concepts. The understanding of novel metaphors in popular science texts does not involve the mapping of concepts from one domain to another, but the mapping of mental images (cf. Tendahl and Gibbs, 2008). The symbolic resources of a language can provide new alternative meanings for communication.

Conceptual metaphors are based on everyday experience and associative perception of reality. Meaning extension of a conceptual metaphor is a neverending cognitive process, which results in meaning evolution, the change of meaning through time (cf. Lakoff and Turner, 1989, p. 186). Abstract thinking and imagination are considered to be mediated through metaphors, for example:

(7) Going out without a plan but merely to partake in the unpredictable and spontaneous public pageant, a characterizing feature of urban life, has grown increasingly rare (Ellin, 2006, p. 102).

According to Merriam-Webster's Dictionary, pageant refers to an elaborate public spectacle illustrative of the history of a place, institution, etc. Nowadays, it is also used to denote a costumed procession, a beauty contest, or the like forming part of public or social festivities.

The metaphor strives to describe and represent the idea in a short way to make a deeper impression on readers. Using metaphors, authors construct a level at which different concepts may be relevant and expand the research imagination.

The function of metaphor is two-fold: cognitive and aesthetic - the brightest feature of metaphor that makes it noticeable and distinguishable from other stylistic devices.

(8) If subsidizing a new venture proves to be necessary, then this should be done in a fast cycle, based on a well-thought-out competitive strategy. This requires rapid, concise assessment of situations rather than being taken by a mirage. Avoiding Fata Morgana is vitally relevant in connection to benefits to be derived from the cloud (Chorafas, 2011, 84). 
Mysterious Fata Morgana is an incredibly complex form of mirage that has historically both fascinated and scared sailors. Fata morgana takes its name from Morgan le Fay, a sorceress of medieval legends and half-sister of King Arthur. Due to her ability to change shape, she was blamed for causing complex mirages over bodies of water. According to Warner (2008), the Normans brought stories of Morgan's magic to Italy, particularly her penchant for luring sailors to an undersea palace with visions of castles in the air. Before the Scientific Revolution, mirages were firmly in the realm of mysticism. Today it is known that such optical illusions are caused by atmospheric conditions, but still sometimes fata morgana is used as a synonym of mirage.

It is important to note that the recognisable elements are still retained in the allusion even when it is altered. Even if the link created by the altered allusion is vague and blur, it can still contribute to the text at different levels, starting from aesthetic interactivity to mental processing.

Allusions as a type of intertextuality enable authors to draw a line to world knowledge and events, demonstrating the universality of past experiences and their modified reoccurrence in a new period of time.

\section{Concluding Remarks}

Professional communication in different contexts (including academic, scientific, technical and other settings) should be studied to examine the development of the language of science and the way it is influenced by history, technology, media, and culture. The potential of all natural language resources may create the endless number of meanings, which update the vocabulary and expand its limits.

Popular science texts provide a good source for reflection over the main types of meaning extension and meaning change in the contemporary English language focused on science. Foregrounding is often manifested through rhetorical strategies (e.g. in the form of stylistic devices, figurative language), causing the reader's attention to shift from what is communicated to how it is communicated.

The application of different language resources in professional communication demonstrates the interpretive function of language in the process of knowledge construction, the role of cognition in information processing, and the interrelation of linguistic and extra-linguistic means.

\section{References}

Bastien, Claude. 1999. Does context modulate or underlie human knowledge? In Anna Cristina Quelhas and Frederico Péreira (eds.), Cognition and Context. Analise psicologica: Lisbonnes. Barthes, Roland. 1968. Elements of Semiology. Hill and Wang.

Bhatia, Vijay K. 1993. Analysing Genre: Language Use in Professional Settings. London: Longman. 
Botha, W. James. 2012. How does language create meaning? A cognitive perspective. South African Journal of Linguistics 13. 5-25. https://doi.org/10.1080/10118063.1995.9724027

Brown, Ellen Hodgson J.D. 2008. Web of Debt: The Shocking Truth about Our Money System and How We Can Break Free. Louisiana: Third Millennium Press.

Carnap, Rudolf. 1937. The Logical Syntax of Language. New York: Harcourt Brace.

Chorafas, Dimitris N. 2011. Cloud Computing Strategies. New York: CRC. https://doi.org/10.1201/9781439834541

Clark, Herbert H. 1996. Using language. Cambridge: Cambridge University Press.

Croft, William and D. Alan Cruse. 2012. Cognitive Linguistics. Cambridge: Cambridge University Press.

Croft, William. 2000. Explaining Language Change. London: Longman.

Davis, Wayne A. 2002. Meaning, Expression, and Thought. New York: Cambridge University Press. https://doi.org/10.1017/CBO9780511498763

Domaneschi, Filippo, Carrea, Elena, Penco Carlo and Alberto Greco. 2016. Selecting presuppositions in conditional clauses. Results from a psycholinguistic experiment. Frontiers in Psychology 6. 149-158. https://doi.org/10.3389/fpsyg.2015.02026

Doncaster, Sarah. 2013. Representations of Nature in Shakespeare's King Lear. [Online]. Available from: http://www.shakespeare-online.com. [Accessed: 24th April 2018].

Doniger, Wendy. 2011. The Implied Spider: Politics and Theology in Myth. New York: Columbia University Press.

Einstein, Albert and Leopold Infeld. 1938[1971]. The Evolution of Physics. The Growth of Ideas from Early Concepts to Relativity and Quanta. Cambridge: Cambridge University Press.

Ellin, Nan. 2006. Integral Urbanism. London: Routledge.

Eskey, David E. 1986. Theoretical foundations. In Fraida Dubin, David E. Eskey and William Grabe (eds.), Teaching Second Language Reading for Academic Purposes. Reading, MA: AddisonWesley.

Evans, Vyvyan and Melanie Green. 2011. Cognitive Linguistics: An Introduction. Edinburgh: Edinburgh University Press.

Fauconnier, Gilles and Mark Turner. 2002. The Way We Think: Conceptual Blending and the Mind's Hidden Complexities. New York: Basic Books.

Fauconnier, Gilles. 1994. Mental Spaces: Aspects of Meaning Construction in Natural Language. New York: Cambridge University Press. https://doi.org/10.1017/CBO9780511624582

Freeman, Margaret. 2006. Blending: A response. Language and Literature 15(1). 107-117. https://doi.org/10.1177/0963947006063528

Gärdenfors, Peter. 2017. Cognitively Oriented Theories of Meaning. Oxford Research Encyclopaedia of Linguistics. https://doi.org/10.1093/acrefore/9780199384655.013.306

Geeraerts, Dirk. 2016. The sociosemiotic commitment. Cognitive Linguistics 27(4). 527-542. https://doi.org/10.1515/cog-2016-0058

Ghiazza, Silvana. 1985. Elementi di Metrica Italiana e Cenni di Retorica, Edizioni Levante. Bari: Edizioni levante.

Gonzalo, Roberto and Karl J. Habermann. 2012. Energy-Efficient Architecture: Basics for Planning and Construction. Boston: Birkhauser-Publishers for Architecture.

Harbison, Robert. 2009. Travels in the History of Architecture. Great Britain: MPG Books Ltd.

Hezaveh, Leyla R., Abdullah, Nurul F. L. and Md Salleh Yaapar. 2014. Revitalizing identity in language: A Kristevan psychoanalysis of Suddenly Last Summer. GEMA Online, Journal of Language Studies 14(2). https://doi.org/10.17576/GEMA-2014-1402-01

Ilinska, Larisa, Platonova, Marina and Tatjana Smirnova. 2015. Information structure of contemporary popular scientific and technical text. In ICT for Language Learning (8th ed.), Italy, Florence, 12-13 November 2015 (pp. 296-300). Padova: Libreriauniversitaria.it edizioni.

Irvine, Martin. 2016. The grammar of meaning making: Sign systems, symbolic cognition, and semiotics. Communication, Culture \& Technology Program. Georgetown University. 1-48. 
Jackendoff, Ray. 1990. Semantic Structures. Cambridge Mass: MIT Press.

Janssens, Leen and Walter Schaeken. 2016. 'But' implicatures: A study of the effect of working memory and argument characteristics. Frontiers in Psychology 7. 159-170. https://doi.org/10.3389/fpsyg.2016.01520

Kövecses, Zoltán. 2015. Where Metaphors Come from. New York: Oxford University Press. https://doi.org/10.1093/acprof:oso/9780190224868.001.0001

Lakoff, George. 1987. Women, Fire, and Dangerous Things: What Categories Reveal about the Mind. Chicago: University of Chicago Press. https://doi.org/10.7208/chicago/9780226471013.001.0001

Lakoff, George, and Mark Turner. 1989. More than Cool Reason: A Field Guide to Poetic Metaphor. Chicago: Chicago University Press. https://doi.org/10.7208/chicago/9780226470986.001.0001

Langacker, Ronald W. 1987. Foundations of Cognitive Grammar (vol. 1). Theoretical Prerequisites. Stanford: Stanford University Press.

Langacker, Ronald W. 1991. Concept, Image, and Symbol. Berlin and New York: Mouton de Gruyter.

Langacker, Ronald W. 1999. Grammar and Conceptualization. Berlin/New York: Mouton de Gruyter. https://doi.org/10.1515/9783110800524

Leech, Geoffrey. 2008. Language in Literature: Style and Foregrounding. Great Briatin: Pearson Education.

Leech, Geoffrey. 1981. Semantics: The Study of Meaning. Harmondsworth: Penguin Books.

Leppihalme, Ritva. 1997. Cultural Bump: An Empirical Approach to the Translation of Allusions. Clevedon: Multilingual Matters Ltd.

Levy-Strauss, Claude. 1978 [2014]. Myth and Meaning. London: Routledge. https://doi.org/10.3138/9781442654112

Montes-Alcalá, Cecilia. (2013). Writing on the border: English y español también. In Imelda MartínJunquera (ed.), Landscapes of Writing in Chicano Literature. USA: Palgrave Macmillan, 213230. https://doi.org/10.1057/9781137353450_19

Pasco, Allan H. (2002). Allusion: A Literary Graft. Charlottesville: Rookwood Press.

Peer, van Willie. 1986. Stylistics and Psychology: Investigations of Foregrounding. Routledge Kegan \& Paul.

Pohl, Gabriela. 2004. Cross-cultural pragmatic failure and implications for language teaching. SLLT $4,1-10$.

Schlefer, Jonathan. 2012. The Assumptions Economists Make. Cambridge: Harvard University Press. https://doi.org/10.4159/harvard.9780674065529

Skrebnev, Yury. 2000. Fundamentals of English Stylistics. М: Астрель.

Sperber, Dan and Deirdre Wilson. 2002. Pragmatics, modularity and mind-reading. Mind \& Language 17. 3-23. https://doi.org/10.1111/1468-0017.00186

Stephens, James. 1975. Francis Bacon and the Style of Science. Chicago: University of Chicago Press.

Tarski, Alfred. 1944. The semantic conception of truth. Philosophy and Phenomenological Research 4. 341-375. https://doi.org/10.2307/2102968

Taylor, John. 2003. Polysemy's paradoxes. Language Sciences $25.637-55$. https://doi.org/10.1016/S0388-0001(03)00031-7

Tendahl, Markus and Raymond. W. Gibbs Jr. 2008. Complementary perspectives on metaphor: Cognitive linguistics and relevance theory. Journal of Pragmatics 3. 1823-1864. https://doi.org/10.1016/j.pragma.2008.02.001

Trask, Robert L. 2004. Language: The Basics. UK: Psychology Press. https://doi.org/10.4324/9780203165287

Wittgenstein, Ludwig. 1974. Tractatus Logico-Philosophicus. Tras. D.F. Pears and B.F. McGuinness. New York: Humanities Press.

Worton, Michael, and Judith Still. 1990. Intertextuality: Theories and Practices. Manchester: Manchester University Press. 